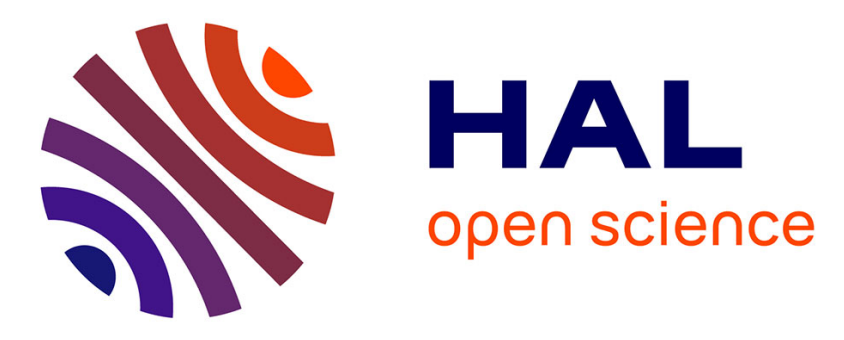

\title{
PIXE analysis and fission track dating of obsidian from South American prehispanic cultures (Colombia, Ecuador)
}

Ludovic Bellot-Gurlet, Thomas Calligaro, Olivier Dorighel, Jean-Claude Dran, Gérard Poupeau, Joseph Salomon

\section{To cite this version:}

Ludovic Bellot-Gurlet, Thomas Calligaro, Olivier Dorighel, Jean-Claude Dran, Gérard Poupeau, et al.. PIXE analysis and fission track dating of obsidian from South American prehispanic cultures (Colombia, Ecuador). Nuclear Instruments and Methods in Physics Research Section B: Beam Interactions with Materials and Atoms, 1999, 150 (1-4), pp.616 - 621. 10.1016/S0168-583X(98)01089-1 . hal-01790745

\section{HAL Id: hal-01790745 \\ https://hal.science/hal-01790745}

Submitted on 12 Jul 2018

HAL is a multi-disciplinary open access archive for the deposit and dissemination of scientific research documents, whether they are published or not. The documents may come from teaching and research institutions in France or abroad, or from public or private research centers.
L'archive ouverte pluridisciplinaire HAL, est destinée au dépôt et à la diffusion de documents scientifiques de niveau recherche, publiés ou non, émanant des établissements d'enseignement et de recherche français ou étrangers, des laboratoires publics ou privés. 


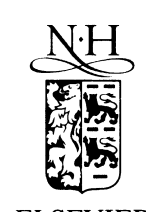

Nuclear Instruments and Methods in Physics Research B 150 (1999) 616-621

\title{
PIXE analysis and fission track dating of obsidian from South American prehispanic cultures (Colombia, Ecuador)
}

\author{
L. Bellot-Gurlet ${ }^{\text {a }}$, Th. Calligaro ${ }^{\text {b }}$, O. Dorighel ${ }^{\text {a,c }}$, J.-C. Dran ${ }^{\text {b,1 }}$, G. Poupeau ${ }^{\text {a,*, }}$, \\ J. Salomon ${ }^{\mathrm{b}}$ \\ a Groupe de Géophysique Nucléaire, CNRS UPRES-A 5025, Université Joseph Fourier, Institut Dolomieu, 15 rue Maurice Gignoux, \\ 38031 Grenoble, France \\ ${ }^{\mathrm{b}}$ Laboratoire de Recherche des Musées de France, CNRS UMR 171, 6 rue des Pyramides, 75041 Paris cedex 01, France \\ ${ }^{\mathrm{c}}$ Université de Paris I Sorbonne, Paris, France
}

\begin{abstract}
In the present work we have coupled PIXE with fission track dating to characterise obsidian artefacts from about 40 archaeological sites of Colombia and Ecuador. PIXE analysis, carried out with the external beam line of the AGLAE tandem accelerator, yields the content in about 15 elements with $Z>8$, whereas fission track dating is applied to ages in excess of about 10000 years. About 120 artefacts were investigated by PIXE, of which 50 were dated by fission tracks. Ages and compositions were compared to those of obsidians from all known geological sources of the region. We show that this double characterisation allows us to determine the number of obsidian sources exploited in an ancient past and to give some insight into obsidian circulation. (c) 1999 Elsevier Science B.V. All rights reserved.
\end{abstract}

Keywords: Obsidian; Provenience studies; PIXE; External beam; Fission track dating

\section{Introduction}

An important issue in archaeology deals with the sources of raw materials used for lithic industry. Among the great variety of analytical techniques applied to provenience studies, PIXE appears as a powerful one, because of its high sensitivity, its non-destructive character and its relatively easy implementation. In particular, this technique was successfully applied to the deter-

\footnotetext{
${ }^{*}$ Corresponding author.; e-mail: poupeau@ujf-grenoble.fr

${ }^{1}$ E-mail: dran@culture.fr
}

mination of obsidian sources since the very beginning of its availability in the early seventies, first for obsidian from Meso-America [1] and then on a wider regional scale, for those from the Pacific area [2-4]. Concerning South America, PIXE was already used for obsidian provenience studies in Chile [5]. The present study, started in 1996 [6], deals with obsidian sourcing in Colombia and Ecuador and relies on the use of the AGLAE PIXE facility of the Laboratoire de Recherche des Musées de France. Obsidians can also be characterised by their formation age as determined by fission-track (FT) dating [7]. We found by using these two techniques that some 
artefacts which have indistinguishable PIXE chemical compositions may have different FT ages and thus must come from different sources. We show that this combination of methods gives some insight into the use of potential obsidian sources by pre-hispanic cultures of the region considered.

\section{Archaeological background and sampling}

The sources of obsidian in South America are linked to the Andean belt. In the region considered in this work, they are associated with volcanoes of the central Cordillera of Colombia and the Cordillera Real of Ecuador. The first evidence for the use of obsidian in stone tool industry in the equatorial Andes seems to date from the first human settlements known, about $10000 \mathrm{BC}$ [8]. Although after Salazar [9] the use of obsidian in Ecuador was initially restricted to geographical areas in the vicinity of obsidian sources, obsidian artefacts were present from the Pacific coast to the Amazonian piedmonts of the Andes since the Formative Period (starting some 3500 BC). They were still encountered in many archaeological sites dating from the Spanish conquest (see Fig. 1). However, it is during the Regional Development period (from $1500 \mathrm{BC}$ to $500 \mathrm{AD}$ ) that obsidian appears to have been the most extensively used [9]. Little is known about obsidian circulation. On the basis of XRF and/or INAA characterisation of about 166 artefacts from 10 Ecuadorian sites $[10,11]$, it was concluded that the Mullumica and Quiscatola sources accounted for more than 95\% of the investigated samples, and that three unknown sources had to be invoked to account for the rest of the data. INAA analysis revealed that obsidian artefacts from two archaeological sites of the Cauca valley in Colombia could originate from the nearby source of Río Hondo [12]. Obsidian characterisation by fission tracks started in the eighties [13,14]. But it was only in 1994 that FT was explicitly applied to provenience studies [15]. Presently, from FT data, it is estimated that at least seven sources were used by prehispanic cultures in Southern Colombia and Ecuador. The

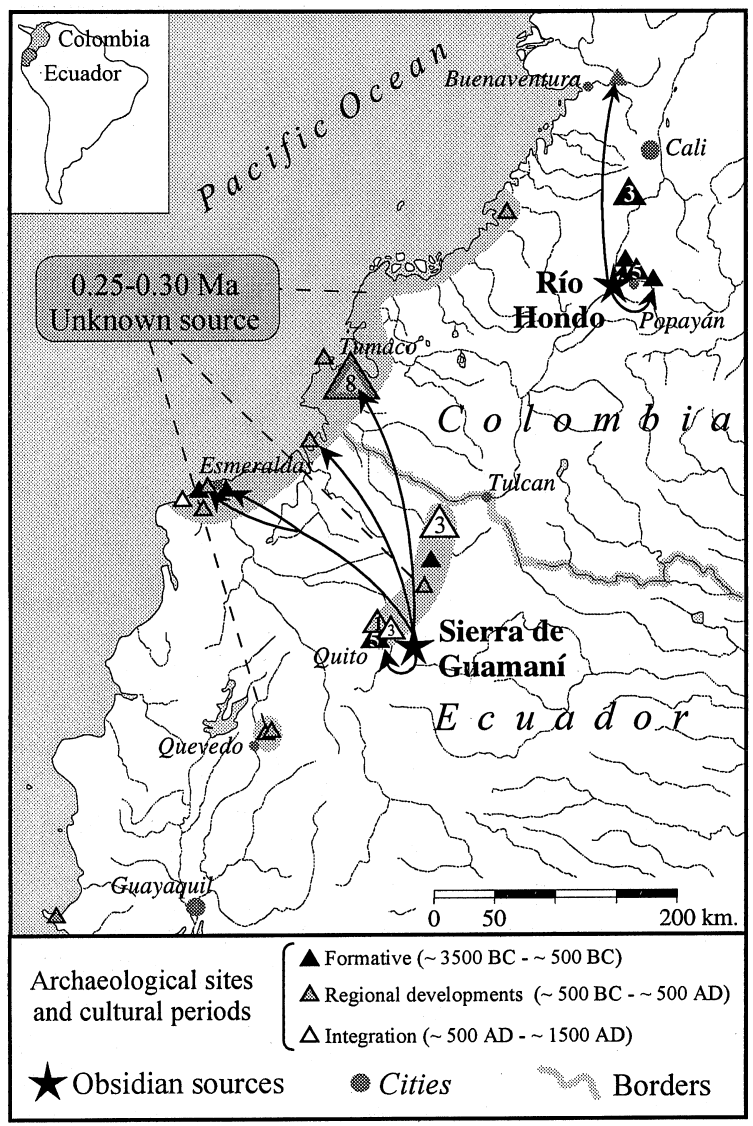

Fig. 1. Schematic map showing the location of the archaeological sites and obsidian sources sampled. The Ecuadorian sources mentionned are located within less than $400 \mathrm{~km}^{2}$ in the Sierra de Guamaní. Arrows joining archaeological sites to sources indicate that at least one artefact from these sites could be traced back to a known source (see text).

combination of PIXE and FT dating allows one to point out the advantages and limitations of each approach [16].

The results we present here deal mainly with obsidian artefacts of the Regional Development period; indeed among the 23 sites involved, 13 pertain to this period, seven to the Formative period and three to the Integration period. All these samples have been supplied to us by the archaeologists working on these sites or have been collected on the field by one of us (O.D.) and their location is given in Fig. 1. 


\section{PIXE analysis}

The AGLAE facility of the Laboratoire de Recherche des Musées de France is based on a 2 MV tandem accelerator (Pelletron 6SDH-2) built by National Electrostatics. Obsidian samples were analysed with an external proton beam [17] impinging perpendicularly to the surface. The exit window is made of a $10-\mu \mathrm{m}$ thick $\mathrm{Al}$ foil and the sample is placed at $3 \mathrm{~mm}$ from it and maintained in a helium atmosphere to reduce absorption of incident protons and emitted X-rays. Under these conditions, the initial proton energy of $3 \mathrm{MeV}$ is reduced to $2.85 \mathrm{MeV}$ at the impact point. Two $\mathrm{Si}(\mathrm{Li})$ detectors oriented at $45^{\circ} \mathrm{C}$ to the proton beam record the $\mathrm{X}$-ray spectrum, being dedicated respectively, to the low energy $\mathrm{X}$-rays $(0.3-10 \mathrm{keV})$ from low- $Z$ major elements of the matrix, and the high energy X-rays (5-40 keV) emitted by trace elements. Using routinely a $0.5 \mathrm{~mm}$ beam diameter and a constant proton dose, each acquisition takes roughly $10 \mathrm{~min}$. X-rays spectra are processed with the GUPIX software [18].

Since we directly analyse hard rock fragments it is not straightforward to use ordinary international geological standards, available as powders, to control the accuracy of our measurements. Instead we used obsidian pieces distributed between laboratories in the framework of an international intercalibration program (Glascock, 1997, in preparation). Reproducibility of data was checked by duplicate measurements on a particular sample (obsidian sample from the Quiscatola-Yanaurcu source).

Archaeological samples are mostly waste flakes remaining after stone tool production or in rare cases as genuine tools of typically a few centimeter for the largest dimension and a thickness less than $0.5-1 \mathrm{~cm}$. Whenever fission track dating (FT) is necessary for source discrimination, small samples are cut as slices with a wire or diamond saw for both PIXE and FT measurements. In that case, PIXE analysis is performed on microprobe-quality diamond polished slices embedded in epoxy resin. For some artefacts non-destructive analysis is absolutely needed for their archaeological importance. Because of the conchoidal fracture of obsidians it is always possible to find a flat surface at the scale of the beam spot for an analysis on natural cleaned surfaces. In order to account for possible local heterogeneity the composition of each sample is measured on three points.

Under these conditions the content of 15 major, minor and trace elements: $\mathrm{Na}, \mathrm{Al}, \mathrm{Si}, \mathrm{Cl}, \mathrm{K}, \mathrm{Ca}$, $\mathrm{Ti}, \mathrm{Mn}, \mathrm{Fe}, \mathrm{Zn}, \mathrm{Ga}, \mathrm{Rb}, \mathrm{Sr}, \mathrm{Zr}$ and $\mathrm{Ba}$ can be determined. The precision given by GUPIX varies between $1 \%$ and $8 \%$, according to the analysed element. This is of the same order as the dispersion observed between several measurements on the same sample. Two elements, namely $\mathrm{Cl}$ and $\mathrm{Ba}$, were discarded for obsidian source identification because of their high variability observed in some samples: the content in $\mathrm{Ba}$ is sometimes highly variable within the same sample and that in $\mathrm{Cl}$ is measured with a large uncertainty (10-15\%), partly due to contents near to the detection limit.

About $8 \%$ of the artefacts were analysed nondestructively using only the sole PIXE technique. Their chemical composition always corresponded to one or another of the compositional groups defined by all the other samples. This suggests that the PIXE data obtained on natural surfaces of artefacts are representative of their bulk composition and thus that burial has no significant effect on the elemental concentration in the sample nearsurface region.

\section{Fission track dating}

Obsidians are dated with the usual "difference" procedure in which a fragment containing unannealed fossil fission tracks is irradiated in a thermal neutron flux [19]. The facility used for our experiments is the Orphée nuclear reactor of the Centre d'Etudes de Saclay. Fission tracks are etched under the same conditions (HF 20\% at $40^{\circ} \mathrm{C}$ for $90-150 \mathrm{~s}$ ) in an irradiated and an unirradiated polished fragments, thus containing respectively fossil+induced tracks and fossil tracks only. The comparison of the diameter distributions of fossil fission tracks (originating from the ${ }^{238} \mathrm{U}$ spontaneous fission) and of the induced ones (produced by the fission of ${ }^{235} \mathrm{U}$ with thermal neutrons) reveals nearly always a shortening of fossil tracks as compared to freshly produced ones. 
This is the consequence of an aging process of the fossil tracks under natural conditions. We therefore apply the plateau-technique of dating [20], which takes into account this effect, to obtain the obsidian formation age. All track measurements are done by optical microscopy in transmission mode and 1250x magnification. More details on our experimental procedure are given elsewhere [21].

There is a sampling bias in the FT characterisation of obsidians relative to PIXE. Whereas all samples are relevant to PIXE analysis, some have to be rejected for FT dating for various reasons: opacity, presence of many crystallites and/or track-like bubbles making track identification uncertain, spurious tracks revealed during the hydrofluoric acid etching process, etc. Thus only about $75 \%$ of the artefacts selected for FT analysis could be dated.

\section{Results}

We analysed by PIXE a total of 22 source samples, coming from Colombia (Río Hondo) and Ecuador (the 6 sources of the Sierra de Guamaní). At the same time 142 artefacts from 35 Ecuadorian and 10 Colombian archaeological sites (Fig. 1) were also analysed. Binary diagrams like the $\mathrm{Mn}$ vs. Sr given in Fig. 2, can usefully illustrate the compositional data and clearly reveal clustering. Indeed the sources sampled define seven discrete compositional groups. One source, Mullumica, presents the unusual characteristic of an heterogeneous composition as shown by its extended compositional field. This heterogeneity was previously mentioned by Asaro et al. [10] and interpreted by these authors as the result of an incomplete mixing of two magmas. The composition of some artefacts is similar to that of known sources: Río Hondo, Quiscatola-Yanaurcu, Mullumica and Callejones. Only three of them exhibit a composition very different from that of the sources reported in Fig. 1.

The consideration of fission track ages leads to a more complex situation. Ecuadorian sources were dated by Bigazzi et al. [22] and the Río Hondo source by Dorighel et al. [21]. Fourty one artefacts from 25 sites were dated [15,21 and unpub data]. The 3D diagram of Fig. 3 shows the combination of compositional and geochronological data. Artefacts with the same compositional characteristics sometimes split into different age groups, implying sources not present in Fig. 1. For 14 artefacts only, age and composition match a known source from which they might come. The

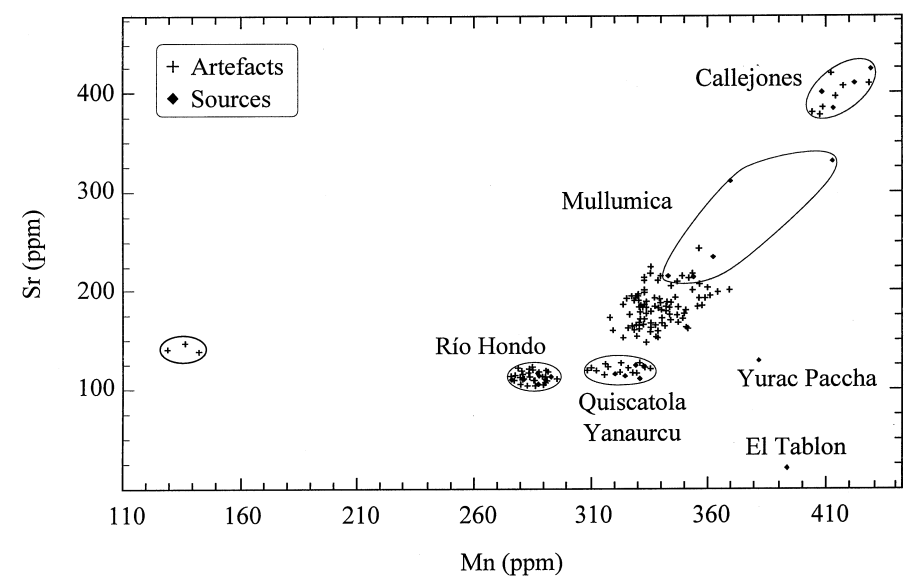

Fig. 2. Binary diagram plotting the Sr content vs. Mn in all the investigated artefacts and source samples. The extended Mullumica source field is secant over that of an important group of artefacts. When dated by FT, artefacts from this group show in general corrected ages in the $0.25-0.30 \mathrm{Ma}$ (18 samples) rather than ages concordant with that of the Mullumica flow (5 samples), implying that most of them come from another source. 


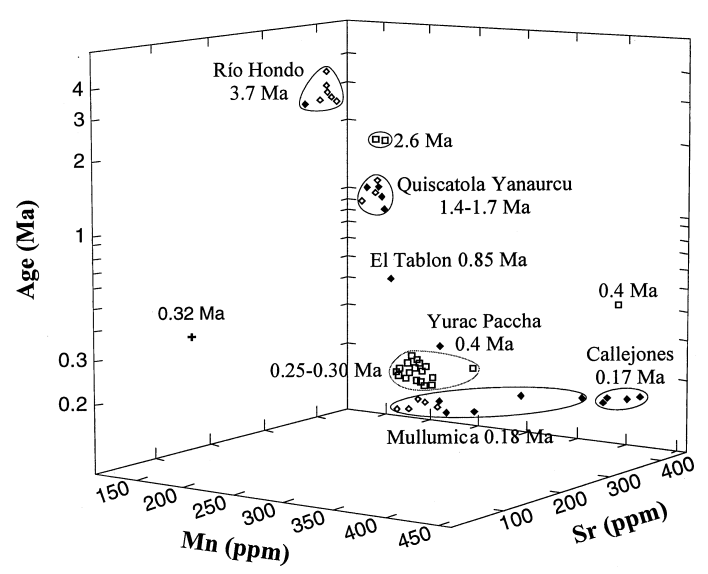

Fig. 3. 3-dimensional diagram based on $\mathrm{Mn}$ and $\mathrm{Sr}$ contents and ages of the source samples and artefacts from Fig. 2 dated by fission tracks.

27 other dated artefacts need to be related to three unknown sources. One of these sources, with an age in the range $0.25-0.30 \mathrm{Ma}$, is represented by 22 samples from 16 archaeological sites.

\section{Archaeological implications}

The first implication of the experimental approach we followed is illustrated by the comparison of Figs. 2 and 3: using only PIXE analysis for obsidian provenience studies in the area considered might lead to an erroneous source attribution, as several sources of different ages appear to have indistinguishable chemical compositions. Fission track dating may help to discriminate between these sources, but a significant fraction of artefacts cannot be dated. However, in spite of these limitations, some conclusions may be drawn from the above PIXE-FT methodology.

First, ancient men living in the investigated area used more obsidian sources than those we know. Whether this is due to a better knowledge of local sources or to the consequence of already established "long-distances" trade systems, remains to be ascertained. Second, the major source of our artefacts collection (shaded areas of Fig. 1) is still unknown. $0.25-0.30 \mathrm{Ma}$ as old one and not the Mullumica source has been postulated by previous authors [10,11]. Third, in the Southern Colombia valley of the Rio Cauca, flowing northwards between two cordilleras and closed in the south by high mountains, only one source seems to correspond to the archaeological artefacts, that of Rio Hondo, located in the high Cauca valley.

Thus the combination of PIXE/FT dating allows us to reveal some trends of the obsidian source distribution in archaeological sites of Southern Colombia and Ecuador. However, some samples are not suitable for this methodology and other potentially complementary techniques of obsidian characterisation are presently under study in (Refs. [23,24] and unpublished data). We hope that a multiparametric approach involving dating, geochemical and structural analyses of obsidian might help in the future to infer unambiguously obsidian provenance.

\section{Acknowledgements}

The authors wish to thank their colleagues of the archaeology and archaeometry communities who generously provided samples and informations: G. Bigazzi (Pisa, Italy), M. Bolaños, M. Villalba, A. Yepez (Quito, Ecuador), J.-F. Bouchard (Paris, France), J. Echeverria (Otavallo, Ecuador), M.D. Glascock (Columbia, USA), C. Gnecco, M. Lahitte, M. Mendez, D. Patiño (Popayán, Colombia), N. Guillaume-Gentil (Neûchatel, Switzerland), M. Guinea (Madrid, Spain), M. Reindel (Bonn, Germany), H. Salgado (Darien, Colombia), K. Stothert (Yale, USA). One of us (O.D.) acknowledges the support of the Institut Français d'Etudes Andines for 1995 and 1997 field trips in Colombia and Ecuador.

\section{References}

[1] K.K. Nielson, M.W. Hill, N.F. Mangelson, F.W. Nelson, Anal. Chem. 48 (1976) 1947.

[2] P. Duerden, J.R. Bird, M.D. Scott, E. Clayton, L.H. Russel, D.D. Cohen, Nucl. Instr. and Meth. 168 (1980) 447.

[3] W.R. Ambrose, P. Duerden, J.R. Bird, Nucl. Instr. and Meth. 191 (1981) 397.

[4] J.R. Bird, in: Museum International 46, UNESCO, Paris, 1994, p. 8. 
[5] A. Seelenfreund, C. Rees, R. Bird, G. Bailey, R. Bercena, V. Duran, Latin American Antiquity 7 (1996) 7.

[6] L. Bellot-Gurlet, Th. Calligaro, O. Dorighel, J.-C. Dran, G. Poupeau, J. Salomon, Intern. Assos. Obsidian Studies Bull. 16 (1996) 3.

[7] G. Poupeau, G. Bigazzi, L. Bellot-Gurlet, O. Dorighel, in: M.-C. Cauvin, A. Gourgaud, B. Gratuze, G. Poupeau, J.-L. Poidevin, C. Chataigner (Eds.), L'obsidienne au Procheet Moyen Orient. Du volcan à l'outil, BAR International Series 738, Hadrian Books, Oxford, 1998, pp. 53-67.

[8] W.J. Mayer-Oakes, R.E. Bell, Current Anthropology 1 (1960) 429.

[9] E. Salazar, in: G. Politis (Eds.), Arqueologia en America Latina Hoy, Fondo de Promocion de la Cultura, Banco Popular, Bogota, 1992, p. 116.

[10] F. Asaro, E. Salazar, H.V. Michel, R.L. Burger, F.H. Stross, Latin American Antiquity 5 (1994) 257.

[11] R.L. Burger, F. Asaro, H.V. Michel, F.H. Stross, E. Salazar, Latin American Antiquity 5 (1994) 228.

[12] C. Gnecco, M. D. Glascock, H. Neff, Internal Report, Missouri University Research Reactor, Columbia, Missouri, 1993, p. 20.

[13] D.S. Miller, G. Wagner, Nucl. Tracks, 5 (1981) 147.

[14] C. Arias, C. Bernardes, G. Bigazzi, F.P. Bonadonna, M.F. Cesar, N.J.C. Hadler, C.M.G. Lattes, J.V. Oliveira,
A.A.M. Osorio, G. Radi, Ciencia e Cultura 38 (1986) 285.

[15] O. Dorighel, G. Poupeau, J.-F. Bouchard, E. Labrin, Bull. Soc. Préhist. Fr 91 (1994) 133.

[16] L. Bellot-Gurlet, G. Poupeau, O. Dorighel, Th. Calligaro, J.-C. Dran, J. Salomon, J. Archaeological Sci. (1998) in press.

[17] Th. Calligaro, J.D. McArthur, J. Salomon, Nucl. Instr. and Meth. Phys. Res. B 109 (1996) 125.

[18] J.A. Maxwell, W.J. Teesdale, T.L. Campbell, Nucl. Instr. and Meth. Phys. Res. B 95 (1995) 407.

[19] G. Wagner, P. Van den Haute, in: Fission-track Dating, Kluwer Academic, Dordrecht, 1992, p. 285.

[20] D. Storzer, G. Poupeau, Compt. Rend. Acad. Sci. Paris 276D (1973) 137.

[21] O. Dorighel O., G. Poupeau, L. Bellot-Gurlet, E. Labrin, in: P. Van den Haute, F. De Corte (Eds.), Advances in Fission-Track Geochronology, Kluwer Academic, Dordrecht, 1998, p. 313.

[22] G. Bigazzi, M. Coltelli, N.J.C. Hadler, A.A.M. Osorio, M. Oddone, E. Salazar, J. South Amer. Earth Sci. 6 (1992) 21.

[23] S. Petrick, R. B. Scorzelli, A. Rossi, G. Poupeau, A. Seelenfreund, J. Hyperfine Interaction (C) 2 (1997) 10.

[24] A.D. Bustamante, S. Petrick, R.B. Scorzelli, A.M. Rossi, G. Poupeau, A. Seelenfreund, J. Hyperfine Interactions (C) (1997), accepted. 